\title{
A Nonaqueous Redox-Matched Flow Battery with Charge Storage in Insoluble Polymer Beads
}

\author{
Dukhan Kim, ${ }^{\text {a,c }}$ Melanie S. Sanford, ${ }^{\text {bcc }}$ Thomas P. Vaid,, ${ }^{\text {b,* }}$ and Anne J. McNeil ${ }^{\mathrm{a}, \mathrm{b}, \mathrm{c}^{*}}$ \\ ${ }^{a}$ Macromolecular Science and Engineering Program, University of Michigan, 2800 Plymouth Rd, Ann Arbor, Michigan, \\ 48109-2800 \\ ${ }^{b}$ Department of Chemistry, University of Michigan, 930 North University Avenue, Ann Arbor, Michigan, 48109-1055 \\ ${ }^{\mathrm{c} J o i n t}$ Center for Energy Storage Research (JCESR), 9700 South Cass Avenue, Argonne, Illinois 60439, United States
}

\begin{abstract}
We describe the nonaqueous redox-matched flow battery (RMFB), where charge is stored on redox-active moieties covalently tethered to non-circulating, insoluble polymer beads and charge is transferred between the electrodes and the beads via soluble mediators with redox potentials matched to the active moieties on the beads. The RMFB reported herein uses ferrocene and viologen derivatives bound to crosslinked polystyrene beads. Charge storage in the beads leads to a high (approximately 1.0-1.7 M) effective concentration of active material in the reservoirs while preventing crossover of that material. The relatively low concentration of soluble mediators $(15 \mathrm{mM})$ eliminates the need for high-solubility molecules to create high energy density batteries. Nernstian redox exchange between the beads and redox-matched mediators was fast relative to the cycle time of the RMFB. This approach is generalizable to many different redox-active moieties via attachment to the versatile Merrifield resin.
\end{abstract}

\section{INTRODUCTION}

In redox flow batteries (RFBs; Scheme 1(a)), redox-active materials are dissolved in two separate solutions, the anolyte and catholyte, which flow past two closely-spaced electrodes where the electrochemical reactions take place. ${ }^{1,2}$ Because the anolyte and catholyte solutions are contained in external tanks, RFBs can be scaled easily and inexpensively to store large amounts of energy, which is advantageous for renewable energy obtained from intermittent wind and solar sources. One current focus in RFB research is on achieving high energy density, which is directly proportional to both the battery voltage (the difference in redox potential between the two redox-active materials) and the concentration of redox-active materials in solution. A high battery voltage is feasible in RFBs that use nonaqueous solvents such as acetonitrile, due to their wide electrochemical windows of up to $5 \mathrm{~V}$ or more ${ }^{3,4}$ compared to $\sim 1.5$ $\mathrm{V}$ in aqueous systems. To take advantage of these wide electrochemical windows, redox-active organic molecules (ROMs) are used as the active materials because they can be synthetically tuned to exhibit high oxidation potentials ${ }^{5-7}$ and low reduction potentials. ${ }^{8-10}$ Additionally, ROMs can be functionalized to create molecules with solubilities of $1 \mathrm{M}$ or greater, ${ }^{11}$ enabling, in theory, high-energy-density organic, nonaqueous RFBs. However, at concentrations near $1 \mathrm{M}$ most ROM solutions become viscous and ionic conductivity decreases, ${ }^{12}$ rendering them less suitable for use in RFBs.

Another issue that must be addressed in RFBs is crossover of the redox-active species between the anolyte and catholyte solutions. Once a redox-active species has crossed over to the opposite electrolyte solution, it is no longer electrochemically active, resulting in a loss in capacity for the RFB. One way that crossover has been addressed is by the creation of "symmetric" RFBs, which can be constructed in two different ways. In the first, the anolyte and catholyte solutions contain the same redox-active element, as in the vanadium RFB, which uses the
$\mathrm{V}^{2+/ 3+}$ couple in the anolyte solution and the $\mathrm{V}^{4+/ 5+}$ couple in the catholyte solution. As a consequence, the vanadium ions that cross over will simply enter into the other redox reaction in the next cycle. The other way to create a symmetric RFB is by using a 1:1 mixture of the positive and negative redox-active materials in both the anolyte and catholyte solutions, as is done in the iron-chromium aqueous RFB wherein the positive redox couple is $\mathrm{Fe}^{2+/ 3+}$ and the negative redox couple is $\mathrm{Cr}^{2+/ 3+} \cdot{ }^{13}$ In each solution only one ion participates in the battery charge and discharge while the other ion is a spectator. While this configuration mitigates the negative effects of crossover, half of the active material is not used and is thus not an efficient use of materials. Symmetric nonaqueous, organic RFBs have been made by using a ROM that can be both reversibly oxidized and reversibly reduced as both the positive and negative $\mathrm{ROM}^{14-16}$ or by using a 1:1 mixture of two ROMs in both the anolyte and catholyte solutions, ${ }^{9}$ as in the iron-chromium RFB. Alternatively, different positive and negative ROMs can be used to make an asymmetric RFB, but that requires the synthesis of oligomeric positive and negative ROMs and/or the use of specialized membranes minimize crossover. ${ }^{17,18}$

An innovative concept, the redox-targeted electrode, was introduced by Wang, Grätzel and coworkers in 2006 ${ }^{19,20}$ and points the way to a system that could simultaneously address several of the issues discussed above. In the redox-targeted electrode (Scheme 1(b)), an insoluble and poorly electrically conducting active material such as $\mathrm{LiFePO}_{4}$ is not in direct electrical contact with the current collector. Instead, two soluble redox-active molecules are in a solution that bathes the $\mathrm{LiFePO}_{4}$. One of the soluble mediators has a redox potential about $0.1 \mathrm{~V}$ positive of $\mathrm{LiFe}^{\mathrm{II}} \mathrm{PO}_{4} / \mathrm{Fe}^{\mathrm{III}} \mathrm{PO}_{4}$, and the other has a redox potential about $0.1 \mathrm{~V}$ negative of $\mathrm{LiFe}^{\mathrm{II}} \mathrm{PO}_{4} / \mathrm{Fe}^{\mathrm{III}} \mathrm{PO}_{4}$. The $\mathrm{LiFePO}_{4}$ is charged by oxidation by the more positive mediator, which in turn is oxidized at the electrode. Discharge happens similarly 
Scheme 1. Previous RFBs, A Redox-Targeted Electrode, and the Redox-Matched Flow Battery

(a) previous RFBs

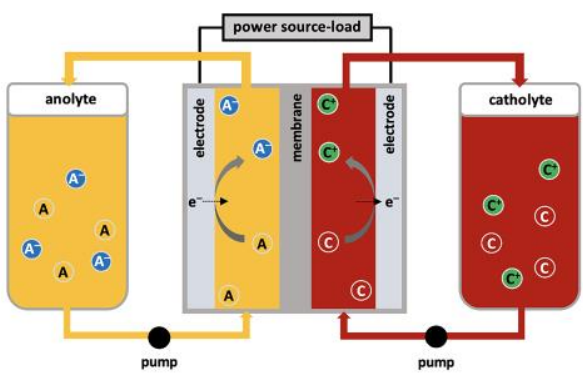

- crossover of the redox-active species

- high concentration solutions difficult to attain (solubility, viscosity) (b) redox-targeted electrode

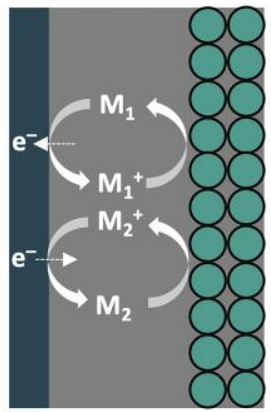

- voltage loss due to separate charge and discharge mediators

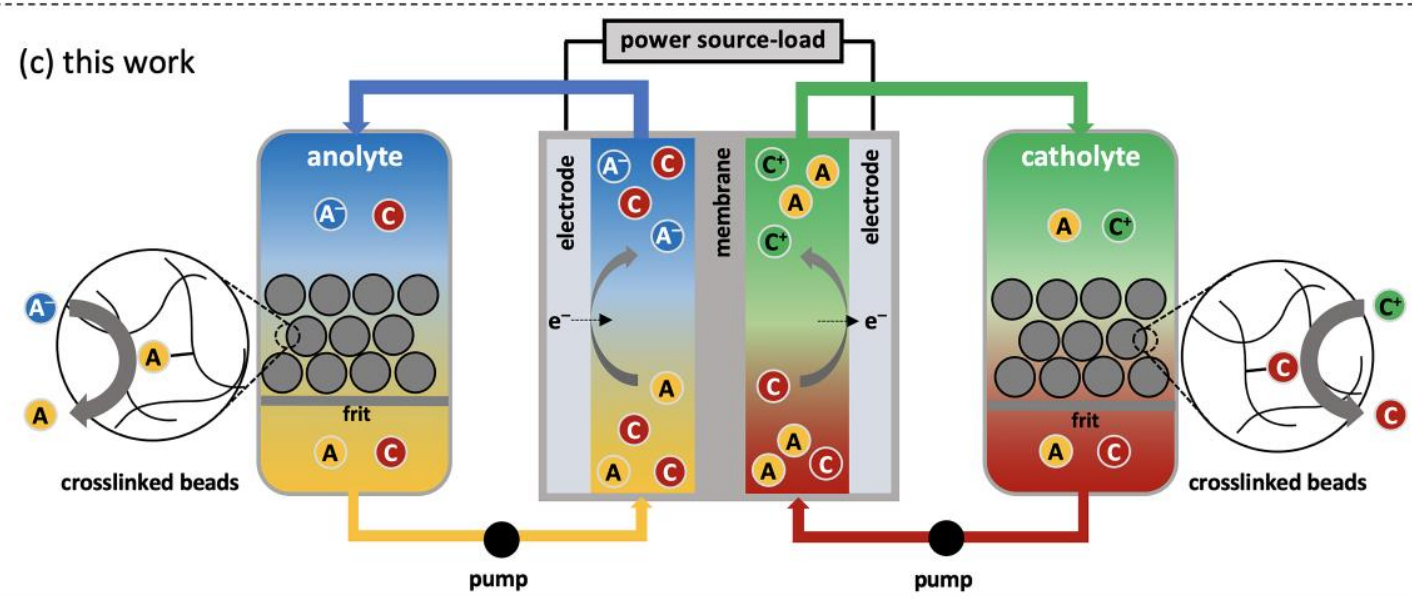

through reduction by the more negative mediator. If the $\mathrm{LiFePO}_{4}$ were used as the positive active material in a flow battery, with the soluble molecular mediators circulating to the electrodes, and a similar setup were used for an insoluble negative active material, it would be possible to create a flow battery with high energy density, approaching that of a lithium-ion battery with the same active materials. One drawback of the system described by Wang and Grätzel is the use of two mediators for each electrode, which leads to a voltaic inefficiency, as charging happens through the higher potential mediator (for the positive electrode) and discharging through the lower potential mediator. In a full flow battery with four mediators (two for each electrode), each with a redox potential $0.1 \mathrm{~V}$ displaced from that of its electrode, there would be a $0.4 \mathrm{~V}$ difference between the charge and discharge voltage of the battery. Since that initial 2006 report, several more redox-targeted inorganic electrodes, or hybrid flow batteries with one redox-targeted electrode, have been reported, ${ }^{21-26}$ as has a full redox-targeted flow battery ${ }^{27}$ and an aqueous RFB with one redox-targeted organic polymer electrode. $^{28}$

Inspired by the redox-targeting strategy described above, we introduce the concept of a redox-matched flow battery (RMFB). In the RMFB (Scheme 1(c)), redox-active molecules are covalently tethered to insoluble polymer beads and these beads act as the charge-storage material. In the RMFB reported herein, the redox-active moieties are a ferrocene derivative for the catholyte beads and a viologen derivative for the anolyte beads. For each bead type there is a matched soluble molecular mediator with a chemical structure similar to the redox-active moiety on the bead, such that the redox potentials are very nearly the same (hence the name "redox-matched" flow battery). In this way, the battery differs from the redox-targeting method described by Wang, Grätzel, and co-workers, where there are two mediators for each insoluble active material. ${ }^{19,20}$ In our RMFB there is only one mediator for each insoluble redox-active material and charging/discharging is driven by the Nernstian potential difference due to the different ratio of oxidized/reduced species in solution versus on the bead. ${ }^{29}$ As shown in Scheme 1, the soluble mediator circulates through the flow battery and is oxidized/reduced at the electrode, then flows past the polymer beads in the reservoir and undergoes redox exchange with the active moieties on the beads. Both the anolyte and catholyte solutions contain a 1:1 mixture of anolyte mediator $(A)$ and catholyte mediator $(C)$, which mitigates the negative effect of crossover of the mediators through the membrane. The soluble species that is in the "wrong" solution merely acts as a spectator and is not involved in the redox reactions at either the electrode or the beads. For example, a viologen in the catholyte solution would remain a dication as the ferrocene derivative is cycled between its neutral and +1 state. Only a small fraction of the viable active material is unused because the vast majority of charge is stored in the beads. With properly chosen polymer beads for functionalization, the effective concentration of active material can be $1 \mathrm{M}$ or more. Yet the dissolved mediators can be at relatively low concentration, in the range of $25 \mathrm{mM}$ or less. Consequently, the soluble species do not need to be engineered for high solubility, and the problems of high-concentration solutions, such as high viscosity, are avoided. 
While this work was in progress, Sevov and Wong reported a redox-targeted electrode based on a crosslinked viologen polymer. $^{30}$ The monomer bis(4-vinyl-benzyl)viologen was polymerized to form heavily crosslinked, insoluble beads that were used as the charge-storage material. However, similar to the inorganic redox-targeted electrodes discussed above, two mediators were used to charge and discharge the crosslinked viologen charge-storage material. In addition, a flow battery was not demonstrated. Herein, we demonstrate an improved version of this redox-targeting approach wherein only a single redoxmatched mediator is used (per electrode), so there is no loss in voltaic efficiency due to multiple mediators with different redox potentials. In addition, rather than requiring a new polymer to be synthesized for each new solid redox-active material, we utilize a synthetic platform that enables wide versatility in the redox-active moieties that can be attached to the polymer beads. Finally, we demonstrate a full RFB system (rather than one electrode) in a manner that should be generalizable to many different redox-active moieties.

\section{RESULTS AND DISCUSSION}

We chose Merrifield resin, which consists of crosslinked polystyrene with chloromethyl functionalities, as our polymer support. Merrifield resin has been extensively used for solid-supported organic reactions, most notably peptide synthesis. ${ }^{31}$ It is commercially available as beads in a variety of sizes, degrees of crosslinking, and degrees of chloromethyl functionalization. The chloromethyl groups offer a convenient handle for covalent attachment of organic moieties. We used beads containing 4.2 mmol of chlorine per gram (determined by elemental analysis (EA) of $\mathrm{C}, \mathrm{H}$, and $\mathrm{Cl}$ ), which translates to a concentration of over $4 \mathrm{M}$ in the dry, unfunctionalized beads. When the chlorine is substituted by the redox-active groups, the volume of the beads increases, and the necessary swelling of the beads by solvent will further increase their volume, but $4 \mathrm{M}$ is an encouragingly high initial effective concentration of active material.

For this initial demonstration of a RMFB, we chose derivatives of the very common and stable redox-active molecules viologen and ferrocene. The starting Merrifield resin beads (xPS-Cl) were functionalized with viologen groups and ferrocene groups by the one-step substitution reactions shown in Figure 1. Treatment of xPS-Cl with 1-methyl-4,4'-bipyridinium iodide in $\mathrm{MeCN}$ at reflux for $48 \mathrm{~h}$ yielded viologen-functionalized beads as the mixed chloride-iodide salt, [xPS-bpy- $\left.\mathrm{Me}^{2+}\right]\left[\mathrm{Cl}^{-}\right]\left[\mathrm{I}^{-}\right]$. Reaction completion was confirmed by disappearance of the $\mathrm{C}-\mathrm{Cl}$ band in the Raman spectrum (at $665 \mathrm{~cm}^{-1}$ ) and in the IR spectrum (at $672 \mathrm{~cm}^{-1}$ ) (see SI, Figure S5 and S6 for spectra). Three rounds of ion exchange with $\mathrm{NH}_{4} \mathrm{PF}_{6}$ yielded the viologen-functionalized beads as the hexafluorophosphate salt, [xPS-bpy-Me $\left.{ }^{2+}\right]\left[\mathrm{PF}_{6}^{-}\right]_{2}$. Both the initial $\left[\mathrm{xPS}-\mathrm{bpy}-\mathrm{Me}^{2+}\right]\left[\mathrm{Cl}^{-}\right]\left[\mathrm{I}^{-}\right]$beads and the ion-exchanged beads, [xPS-bpy- $\left.\mathrm{Me}^{2+}\right]\left[\mathrm{PF}_{6}{ }^{-}\right]_{2}$, were examined by EA for $\mathrm{C}, \mathrm{H}, \mathrm{N}, \mathrm{Cl}$, and $\mathrm{I}$, and the $\left[\mathrm{xPS}-\mathrm{bpy}-\mathrm{Me}^{2+}\right]\left[\mathrm{PF}_{6}{ }^{-}\right]_{2}$ beads were additionally analyzed for $\mathrm{F}$ content. There was no fractional conversion to $\left[\mathrm{xPS}-\mathrm{bpy}-\mathrm{Me}^{2+}\right]\left[\mathrm{Cl}^{-}\right]\left[\mathrm{I}^{-}\right]$and fractional ion-exchange to [xPSbpy- $\left.\mathrm{Me}^{2+}\right]\left[\mathrm{PF}_{6}{ }^{-}\right]_{2}$ that was consistent with the EA data for both sets of beads. However, an assumption of $75 \%$ conversion in the initial functionalization reaction to create [xPS-bpy$\left.\mathrm{Me}^{2+}\right]\left[\mathrm{Cl}^{-}\right]\left[\mathrm{I}^{-}\right]$, followed by $95 \%$ ion exchange to give [xPS-bpy$\left.\mathrm{Me}^{2+}\right]\left[\mathrm{PF}_{6}^{-}\right]_{2}$, gives a calculated EA that agrees reasonably well with the experimental EA mass \% for $\mathrm{N}$ (3.80 calc, 3.44 exp), $\mathrm{Cl}$ (1.84 calc, 1.69 exp), and I (0.86 calc, 0.93 exp). Full details are provided in the SI.
The ferrocene-functionalized beads were synthesized by the reaction of xPS-Cl with ferrocenecarboxylic acid and ${ }^{\mathrm{i}} \mathrm{Pr}_{2} \mathrm{NEt}$ in $\mathrm{DMF}$ at $60^{\circ} \mathrm{C}$ for $24 \mathrm{~h}$, yielding xPS-Fc. Raman spectroscopy of the ferrocene beads was not possible due to fluorescence of the ferrocene functionalities. Instead, reaction progress/completion was checked by IR spectroscopy (SI, Figure S5). The C-Cl band at $672 \mathrm{~cm}^{-1}$ disappeared after reaction, and a $\mathrm{C}=\mathrm{O}$ band at $1714 \mathrm{~cm}^{-1}$ due to the ester linkage appeared. Elemental analysis for $\mathrm{C}, \mathrm{H}, \mathrm{N}$, and $\mathrm{Cl}$ agreed most closely with conversion of $70 \%$ of the chloromethyl groups, and with 0.16 equiv of residual DMF per monomer unit (of any kind). Both bead types were soaked in electrolyte solution $\left(\mathrm{CH}_{3} \mathrm{CN}, 0.50 \mathrm{M}\left[\mathrm{NBu}_{4}\right]\left[\mathrm{PF}_{6}\right]\right)$ and, as shown in Figure S9 of the SI, CVs of those solutions showed that no electroactive species were leached from the beads.

The soluble mediators, shown in Figure 1, were chosen to have structures analogous to the redox-active moieties on the polymer beads, such that their redox potentials would be very similar. Cyclic voltammetry $\left(\mathrm{CH}_{3} \mathrm{CN}, 0.50 \mathrm{M}\left[\mathrm{NBu}_{4}\right]\left[\mathrm{PF}_{6}\right]\right)$ showed that the ferrocene mediator, FcR, has an $E_{1 / 2}=+0.255$ $\mathrm{V}$ (vs ferrocene ${ }^{+/ 0}$ ), while the viologen mediator [Bn-bpy$\left.\mathrm{Me}^{2+}\right]\left[\mathrm{PF}_{6}^{-}\right]_{2}$ has $E_{1 / 2}=-0.785 \mathrm{~V}$ and $-1.204 \mathrm{~V}$ (vs ferrocene ${ }^{+/ 0}$ ). Only the first viologen reduction was used in the RMFB, affording a nominal voltage of $1.04 \mathrm{~V}$.

For the soluble redox mediators to diffuse into the beads to undergo redox exchange, as depicted in Scheme 1, the beads must swell in the battery solvent/electrolyte system. Due to the high concentration of redox-active moieties in the beads, it is likely that self-exchange between tethered groups will facilitate electron transfer to the far interior of the beads so that it is not necessary for mediator to diffuse into the bead center. It is necessary, however, that the $\mathrm{PF}_{6}-$ counterions move fully into and out of the beads to balance every charge transferred. To evaluate bead swelling we placed a known mass $(\sim 100 \mathrm{mg})$ of beads in a standard $5 \mathrm{~mm}$ NMR tube, added an excess of a solvent, and measured the change in height of the column of beads after $2 \mathrm{~h}$. Our calibration of the NMR tubes indicated a volume of $130 \mu \mathrm{L}$ per $\mathrm{cm}$ of height. The measured volume change was multiplied by a factor of 0.74 (the packing fraction of closepacked spheres) to account for the interstitial spaces between the beads. The swelling of both bead types, xPS-Fc and [xPSbpy- $\left.\mathrm{Me}^{2+}\right]\left[\mathrm{PF}_{6}{ }^{-}\right]_{2}$, was measured in $\mathrm{CH}_{3} \mathrm{CN}$, where it was 0.77 $\mathrm{mL} / \mathrm{g}$ for the $\mathrm{xPS}-\mathrm{Fc}$ and $0.96 \mathrm{~mL} / \mathrm{g}$ for the [xPS-bpy$\left.\mathrm{Me}^{2+}\right]\left[\mathrm{PF}_{6}^{-}\right]_{2}$. The bead swelling was also evaluated by optical microscope images of a statistical sample of dry and swollen beads, which yielded similar results (Figure S7 and Table S1). The swelling of both bead types represents a solvent content of the beads that should enable transport of molecular species into and out of the beads during redox exchange, while not excessively increasing the bead volumes such that the concentration of active species becomes diluted (decreasing the energy density of the RMFB). The concentration of redox-active moieties in the $\mathrm{CH}_{3} \mathrm{CN}$-swollen beads is roughly $1.0 \mathrm{M}$ in the viologen beads and $1.7 \mathrm{M}$ in the ferrocene beads.

For the functionalized polymer beads to serve as the chargestorage material in a RMFB, they must undergo electron exchange with the dissolved mediators on a timescale that is fast compared to one charge or discharge half-cycle of the battery. We therefore sought to determine the rate of these redox-exchange reactions before using them in a RFB, but to do so it was 
Functionalized beads

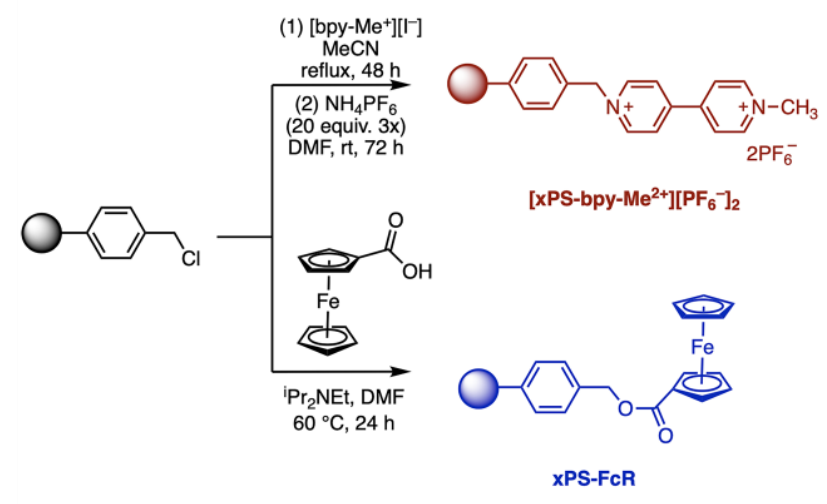

Redox-matched flowable mediators
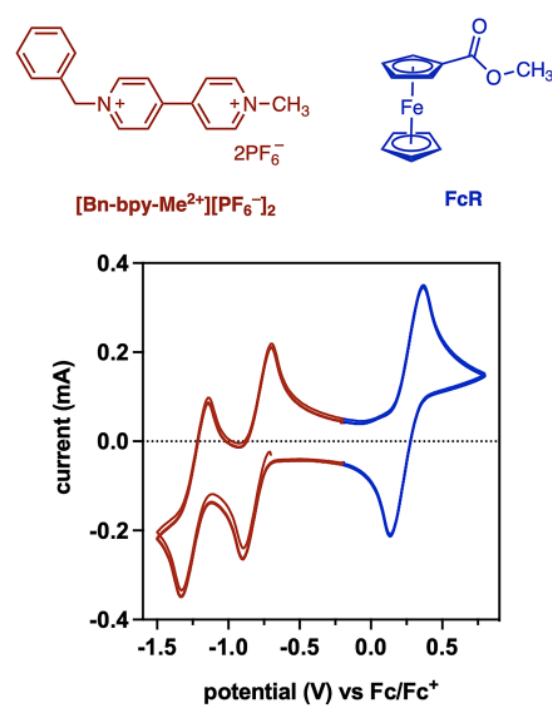

Figure 1. Syntheses of the two functionalized beads (top) and structures of the redox-matched mediators and a cyclic voltammogram of a mixed solution of $5 \mathrm{mM}$ of each in $\mathrm{CH}_{3} \mathrm{CN}$ with $0.50 \mathrm{M}$ $\left[\mathrm{NBu}_{4}\right]\left[\mathrm{PF}_{6}\right]$ at a glassy carbon electrode (bottom).

necessary to measure the individual concentrations of the same ROM in two different oxidation states (e.g., FcR and $\mathrm{FcR}^{+}$) in a mixed solution-something that $\mathrm{CV}$ using a standard disk electrode does not do well. An ultramicroelectrode, on the other hand, yields CVs of the type shown in Figure $2 \mathrm{~b}\left(\mathrm{FcR}, \mathrm{FcR}^{+}\right.$, and a 1:1 mixture of FcR and $\left.\mathrm{FcR}^{+}\right)$and Figure $2 \mathrm{~d}(\mathrm{Bn}-\mathrm{bpy}-$ $\mathrm{Me}^{2+}, \mathrm{Bn}-\mathrm{bpy}-\mathrm{Me}^{+}$, and a 1:1 mixture of $\mathrm{Bn}-\mathrm{bpy}-\mathrm{Me}^{2+}$ and $\mathrm{Bn}-$ bpy- $\left.\mathrm{Me}^{+}\right)$. The difference between the current at the oxidative plateau and the current at the reductive plateau in Figure $2 b$ is proportional to the total concentration of $\mathrm{FcR}$ and $\mathrm{FcR}^{+}$present, with the absolute value of the anodic current proportional to the FcR concentration and the absolute value of the cathodic current proportional to the $\mathrm{FcR}^{+}$concentration. ${ }^{32}$ The direct proportionality of the anodic and cathodic currents to the concentrations of $\mathrm{FcR}$ and $\mathrm{FcR}^{+}$, respectively, holds only if $\mathrm{FcR}$ and $\mathrm{FcR}^{+}$ have similar diffusion coefficients in the solvent/electrolyte system examined; the equivalence of the anodic and cathodic currents in the $\mathrm{CV}$ of a $1: 1$ solution of $\mathrm{FcR}$ and $\mathrm{FcR}^{+}$in Figure $2 \mathrm{~b}$ confirms this to be the case. That is also true for Bn-bpy$\mathrm{Me}^{2+}$ and $\mathrm{Bn}-\mathrm{bpy}-\mathrm{Me}^{+}$, as indicated by the CVs in Figure 2d.
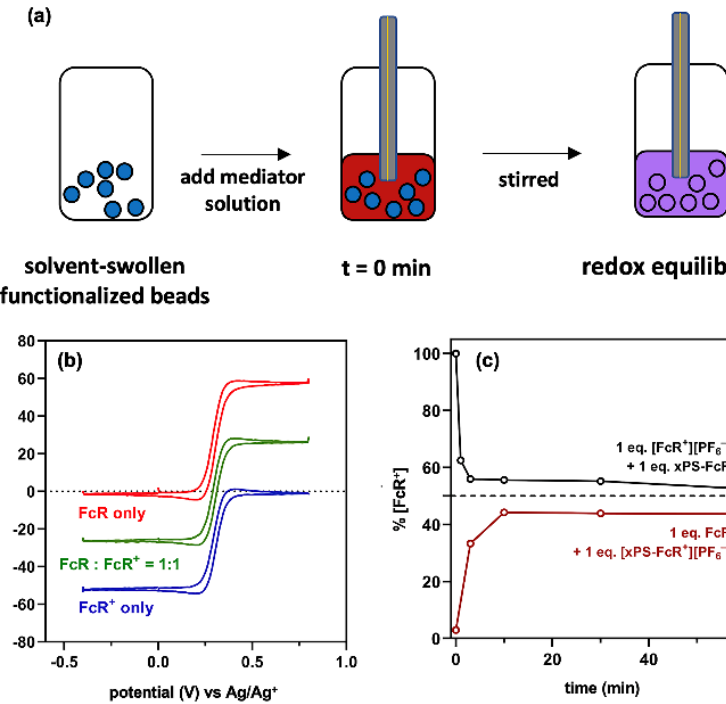

$\mathbf{t}=\mathbf{0} \min$

redox equilibrium
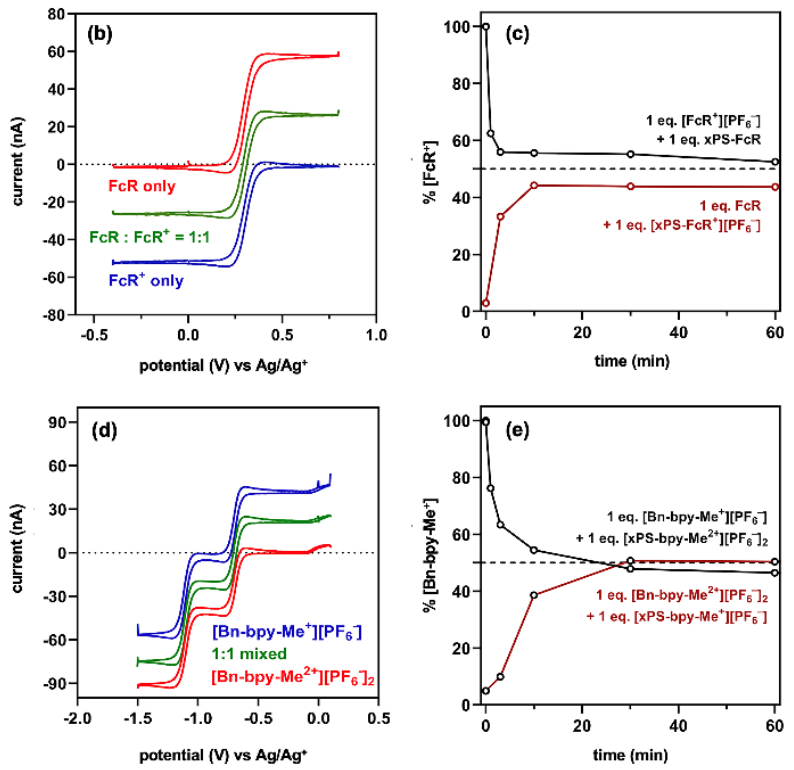

Figure 2. (a) Setup for monitoring redox exchange reactions over time using an ultramicroelectrode (Pt disk, $10 \mu \mathrm{m}$ diameter). (b) Ultramicroelectrode CVs of $5.0 \mathrm{mM} \mathrm{FcR,} 5.0 \mathrm{mM} \mathrm{FcR}^{+}$, and 2.5 $\mathrm{mM}$ each of FcR and $\mathrm{FcR}^{+}$. (c) Change in solution-phase fraction of $\mathrm{FcR}^{+}$over time as $\mathrm{FcR}^{+}$interacts with $\mathrm{xPS}-\mathrm{Fc}$ and $\mathrm{FcR}$ interacts with $\mathrm{xPS}-\mathrm{Fc}^{+}$. (d) Ultramicroelectrode $\mathrm{CVs}$ of $5.0 \mathrm{mM}$ Bn-bpy$\mathrm{Me}^{2+}, 5.0 \mathrm{mM}$ Bn-bpy-Me $\mathrm{Me}^{+}$, and $2.5 \mathrm{mM}$ each of $\mathrm{Bn}-\mathrm{bpy}-\mathrm{Me}^{2+}$ and $\mathrm{Bn}-\mathrm{bpy}-\mathrm{Me}^{+}$. (e) Change in solution-phase fraction of Bn-bpy-Me $\mathrm{Me}^{+}$ over time as Bn-bpy-Me ${ }^{+}$interacts with xPS-bpy-Me ${ }^{2+}$ and Bn-bpy$\mathrm{Me}^{2+}$ interacts with xPS-bpy-Me+.

The rate of redox equilibration between the beads and dissolved mediators was determined by the procedure shown in Figure 2a. First, a measured quantity of beads was placed in a vial (in a nitrogen-filled glovebox) with a solution of $0.50 \mathrm{M}$ $\left[\mathrm{NBu}_{4}\right]\left[\mathrm{PF}_{6}\right]$ in $\mathrm{CH}_{3} \mathrm{CN}$ to swell the beads. The excess liquid was decanted after $30 \mathrm{~min}$. To the swollen beads was added a solution of an equivalent molar amount of its redox-matched mediator in the oxidation state opposite that of the redox moieties on the beads, and the change in redox state of the solutionphase species was monitored. For example, for the xPS-Fc beads, a solution containing one equivalent of $\left[\mathrm{FcR}^{+}\right]\left[\mathrm{PF}_{6}^{-}\right]$(relative to the amount of redox-active Fc moieties on the beads) was added, such that at equilibrium there would be a 1:1 mixture of $\mathrm{FcR}$ and $\mathrm{FcR}^{+}$in solution (assuming that the solutionphase FcR and the bead-bound Fc moiety have the same redox potential). The suspension was gently stirred and the stirring paused to obtain CVs with the ultramicroelectrode. In separate experiments, the equilibrium was approached from the other direction; that is, the oxidized form of the ferrocene beads, [xPS$\left.\mathrm{Fc}^{+}\right]\left[\mathrm{PF}_{6}{ }^{-}\right]$, and the reduced form of the viologen beads, [xPSbpy- $\left.\mathrm{Me}^{+}\right]\left[\mathrm{PF}_{6}^{-}\right]$, were prepared, and each was treated with their corresponding redox-matched mediator in the opposite oxida- 
tion state. In all four experiments the solutions came to equilibrium with an approximate 1:1 mixture of oxidized and reduced species in solution, as expected (Figure $2 \mathrm{c}$ and $2 \mathrm{e}$ ). As shown in Figure 2c, the ferrocene systems came to equilibrium quickly, with the oxidation of xPS-Fc near equilibrium in 3 min and the reduction of $\left[\mathrm{xPS}_{-} \mathrm{Fc}^{+}\right]\left[\mathrm{PF}_{6}{ }^{-}\right]$near equilibrium in $10 \mathrm{~min}$. The viologen system was slower to equilibrate, reaching near-equilibrium in $10 \mathrm{~min}$ and full equilibrium in $30 \mathrm{~min}$, in both the oxidative and reductive redox exchanges. ${ }^{33}$ Separate experiments in our flow battery reservoirs, not connected to the electrode cell but simply recirculating the electrolyte, showed a similarly fast redox exchange between the beads and solution-phase mediators (see SI, Figure S10). Overall, these results show that the beads should charge and discharge sufficiently quickly to function in a RMFB, where the charge or discharge times will be at least $60 \mathrm{~min}$ (corresponding to a $1 \mathrm{C}$ rate).

Initial attempts at full RMFBs used the nonselective mesoporous separators Celgard 2500 or Daramic 175 as the membrane. These membranes are often preferred over ion-exchange membranes because they are more stable in organic solvents and have lower resistance to ion transport. However, they allow relatively fast crossover of ROMs. ${ }^{34}$ We expected that the use of 1:1 solutions of FcR and $\left[\mathrm{Bn}-b p y-\mathrm{Me}^{2+}\right]\left[\mathrm{PF}_{6}{ }^{-}\right]_{2}$ in both the anolyte and catholyte solutions would mitigate the negative effects of that crossover. However, we observed poor capacity utilization of the beads in the RMFBs assembled with either Celgard or Daramic separators (Figure S15). We hypothesized that in those RMFBs the redox exchange between the mediators and the polymer beads is slow relative to the rate of crossover of redox-active material, resulting in incomplete utilization of the redox-active material in the beads. We therefore performed a separate investigation of crossover rates in our RFB system with these separators compared to a Fumasep FAP-375-PP anion-exchange membrane.

Solutions that were $15 \mathrm{mM}$ in both $\left[\mathrm{Bn}-\mathrm{bpy}-\mathrm{Me}^{2+}\right]\left[\mathrm{PF}_{6}^{-}\right]_{2}$ and FcR were placed on both sides of our RFB setup with no polymer beads present (see SI for details, and Figure S8 for photographs of the RMFB setup). While circulating at $20 \mathrm{~mL} / \mathrm{min}$, the battery was charged to $1.40 \mathrm{~V}(0.36 \mathrm{~V}$ greater than the nominal battery voltage). Circulation was stopped and the concentrations of Bn-bpy-Me $\mathrm{Me}^{2+}$ and $\mathrm{Bn}-\mathrm{bpy}-\mathrm{Me}^{+}$in the anolyte solution were determined by ultramicroelectrode $\mathrm{CV}$, which indicated that the battery was $95 \%$ charged. Circulation was then continued with no potential applied, and the circulation stopped periodically to monitor the decay in $\mathrm{Bn}-\mathrm{bpy}-\mathrm{Me}^{+}$concentration and increase in Bn-bpy- $\mathrm{Me}^{2+}$ concentration, as shown in Figure 3 . That discharge can be due to either $\mathrm{Bn}-\mathrm{bpy}-\mathrm{Me}^{+}$passing through the separator from the anolyte solution to the catholyte solution, or $\mathrm{FcR}^{+}$passing from the catholyte solution to the anolyte solution and oxidizing Bn-bpy- $\mathrm{Me}^{+}$. With a Daramic 175 separator, the charge of the anolyte solution dropped to $72 \%$ after $60 \mathrm{~min}$. That discharge is fast enough that it may lead to incomplete charge/discharge of the polymer beads in a RMFB. A similar experiment was performed under identical conditions except for the use of a Fumasep FAP-375-PP anionexchange membrane. In that case, as shown in Figure 3, the discharge due to crossover was significantly slower, with the viologen charge decreasing from $95 \%$ to $93 \%$ over $60 \mathrm{~min}$ and to $91 \%$ over $120 \mathrm{~min}$. (This data is shown in Figures S11-S14 of the SI.) We therefore used Fumasep FAP-375-PP membrane in the following RMFB experiments.

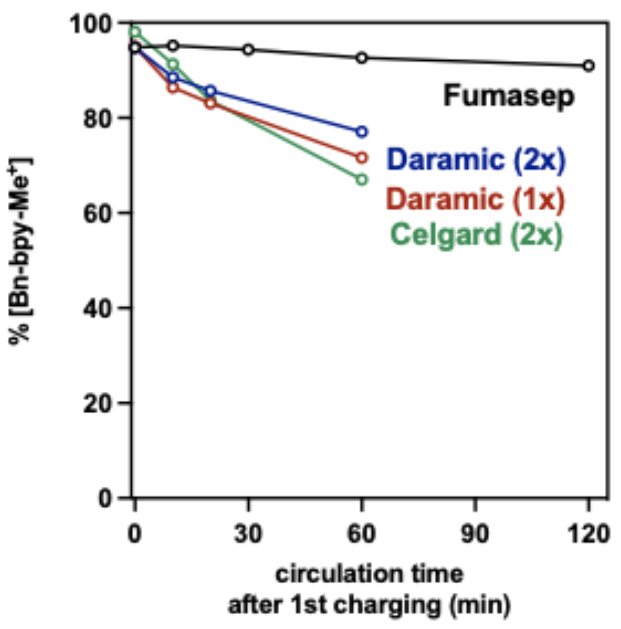

Figure 3. The change in concentration of $\left[\mathrm{Bn}-b p y-\mathrm{Me}^{+}\right]\left[\mathrm{PF}_{6}{ }^{-}\right]$in the anolyte solution after the RFB (with no beads) has been charged and then circulation continued with no electrical charging or discharging, with a Fumasep anion-exchange membrane, Daramic mesoporous membrane (1 or 2 layers), or 2 layers of Celgard mesoporous membrane.

A flow battery was set up with the initial conditions described above $\left(12 \mathrm{~mL}\right.$ of solution in each reservoir, $\mathrm{CH}_{3} \mathrm{CN}, 0.50 \mathrm{M}$ $\left[\mathrm{NBu}_{4}\right]\left[\mathrm{PF}_{6}\right], 15 \mathrm{mM}$ in both $\left[\mathrm{Bn}-\mathrm{bpy}-\mathrm{Me}^{2+}\right]\left[\mathrm{PF}_{6}{ }^{-}\right]_{2}$ and $\left.\mathrm{FcR}\right)$ with no beads present. The RFB was charged and discharged galvanostatically at a current of $10 \mathrm{~mA}$ to cutoff voltages of $1.40 \mathrm{~V}$ (charge) and $0.50 \mathrm{~V}$ (discharge). The charge-discharge curves for 5 cycles are shown in Figure 4a. The theoretical capacity for this cell is $4.82 \mathrm{mAh}$, and $84 \%$ of that capacity was attained with no beads present (see Figure $4 \mathrm{~b}$ ). Next the xPS-Fc beads were added to the catholyte reservoir and [xPS-bpy$\left.\mathrm{Me}^{2+}\right]\left[\mathrm{PF}_{6}^{-}\right]_{2}$ beads were added to the anolyte reservoir. The quantity of beads added to each reservoir contained $0.180 \mathrm{mmol}$ of redox-active moiety, such that the battery capacity would double if the full redox capacity of the beads was utilized. The RMFB was then cycled 30 times, and the charge-discharge curves are shown in Figure 4a while the capacities are shown in Figure 4b. After the addition of 1 equiv of beads, the average discharge capacity increased to $6.16 \mathrm{mAh}$, representing a $52 \%$ increase. When 2 equiv of beads were added, the average discharge capacity increased further to $8.56 \mathrm{mAh}$, representing a $112 \%$ increase over the battery without beads. Combined, these data demonstrate that charge can be efficiently stored on insoluble polymer beads and that charging can occur through solution-based mediators with matched redox potentials, highlighting the unique advantages of our generalizable RMFB system. Nevertheless, the net $4.51 \mathrm{mAh}$ increase in capacity (for 2 equiv of beads) only corresponds to $47 \%$ of the theoretical $9.64 \mathrm{mAh}$ capacity contained in those beads. Post-run CVs of the electrolyte solutions (Figure S16 in the SI) show that both anolyte and catholyte solutions are essentially identical to those present before cycling, indicating that preferential crossover of the mediators, or their decomposition, is not an issue. Future studies will focus on identifying the inefficiencies (e.g., the interaction of current, flow rate, concentration of mediators, quantity of beads present, etc., and their effect on capacity utilization) with the long-term goal of further increasing these storage capacities. 

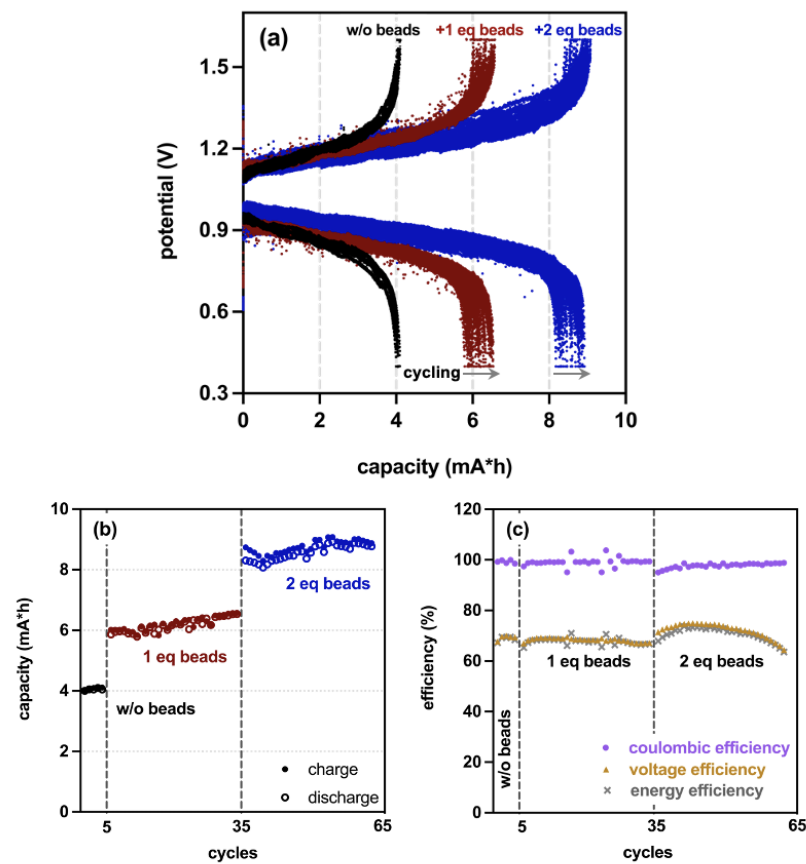

Figure 4. (a) Charge-discharge curves for the RMFB with no beads (black, 5 cycles), 1 equiv of beads (red, 30 cycles), and 2 equiv of beads (blue, 30 cycles), (b) capacity versus cycle number for each battery setup (capacity is increasing during cycling), and the (c) coulombic, voltaic, and energy efficiencies of each battery.

\section{CONCLUSIONS}

The RMFB reported herein demonstrates an effective method for storing charge in a RFB on insoluble crosslinked polymer beads. Merrifield resin serves as a convenient substrate for the synthesis of ferrocene- and viologen-functionalized beads, and promises to be a versatile platform for the synthesis of polymer beads with other tethered redox-active moieties. These functionalized beads undergo redox exchange with their redoxmatched soluble mediators on the relatively fast timescale of several minutes, which enables a Nernstian equilibration between beads and mediators in the reservoirs of a functioning RMFB. The RMFB architecture enables a high theoretical energy density without the requirement of high-concentration solutions, and without the possibility of crossover of the active material on the beads. While there is not yet complete utilization of the redox equivalents on the beads, studies are underway to modify the beads and/or flow battery operating parameters to capture the full capacity of the functionalized polymer beads.

\section{ASSOCIATED CONTENT}

\section{Supporting Information}

Synthetic methods and characterization, including NMR, IR, and Raman spectra. Bead swelling images and data, details of electrochemical methods, image of the flow battery system and a reservoir, data from bead-mediator redox exchange in reservoir, crossover experiments with various membranes, RMFB cycling with a Celgard membrane, and RFB with added XPS- $\mathrm{Cl}$ beads.

\section{AUTHOR INFORMATION}

\section{Corresponding Authors}

*Anne J. McNeil - ajmcneil@umich.edu

*Thomas P. Vaid - vaidt@umich.edu

\section{ORCID}

Dukhan Kim - 0000-0002-5190-2667

Melanie S. Sanford - 0000-0001-9342-9436

Thomas P. Vaid - 0000-0003-4597-0847

Anne J. McNeil - 0000-0003-4591-3308

\section{ACKNOWLEDGMENT}

This research was supported by the Joint Center for Energy Storage Research (JCESR), a U.S. Department of Energy, Energy Innovation Hub. Prof. Adam Matzger assisted in the collection of Raman spectra.

\section{REFERENCES}

Noack, J.; Roznyatovskaya, N.; Herr, T.; Fischer, P. The Chemistry of Redox-Flow Batteries. Angew. Chem. Int. Ed. 2015, 54 (34), 9776-9809. https://doi.org/10.1002/anie.201410823.

Winsberg, J.; Hagemann, T.; Janoschka, T.; Hager, M. D.; Schubert, U. S. Redox-Flow Batteries: From Metals to Organic Redox-Active Materials. Angew. Chem. Int. Ed. 2017, 56 (3), 686-711. https://doi.org/10.1002/anie.201604925.

Ue, M.; Ida, K.; Mori, S. Electrochemical Properties of Organic Liquid Electrolytes Based on Quaternary Onium Salts for Electrical Double-Layer Capacitors. J. Electrochem. Soc. 1994, 141 (11), 2989. https://doi.org/10.1149/1.2059270.

Darling, R. M.; Gallagher, K. G.; Kowalski, J. A.; Ha, S.; Brushett, F. R. Pathways to Low-Cost Electrochemical Energy Storage: A Comparison of Aqueous and Nonaqueous Flow Batteries. Energy Environ. Sci. 2014, 7 (11), 3459 3477. https://doi.org/10.1039/C4EE02158D.

Yan, Y.; Robinson, S. G.; Sigman, M. S.; Sanford, M. S. Mechanism-Based Design of a High-Potential Catholyte Enables a 3.2 V All-Organic Nonaqueous Redox Flow Battery. J. Am. Chem. Soc. 2019, 141 (38), 15301-15306. https://doi.org/10.1021/jacs.9b07345.

Yan, Y.; Vaid, T. P.; Sanford, M. S. Bis(Diisopropylamino)Cyclopropenium-Arene Cations as High Oxidation Potential and High Stability Catholytes for Non-Aqueous Redox Flow Batteries. J. Am. Chem. Soc. 2020, 142 (41), 1756417571. https://doi.org/10.1021/jacs.0c07464.

Silcox, B.; Zhang, J.; Shkrob, I. A.; Thompson, L.; Zhang, L. On Transferability of Performance Metrics for Redox-Active Molecules. J. Phys. Chem. C 2019, 123 (27), 16516-16524. https://doi.org/10.1021/acs.jpcc.9b02230.

Xing, X.; Liu, Q.; Xu, W.; Liang, W.; Liu, J.; Wang, B.; Lemmon, J. P. All-Liquid Electroactive Materials for High Energy Density Organic Flow Battery. ACS Appl. Energy Mater. 2019, 2 (4), 2364-2369. https://doi.org/10.1021/acsaem.8b01874.

Duan, W.; Huang, J.; Kowalski, J. A.; Shkrob, I. A.; Vijayakumar, M.; Walter, E.; Pan, B.; Yang, Z.; Milshtein, J. D.; Li, B.; Liao, C.; Zhang, Z.; Wang, W.; Liu, J.; Moore, J. S.; Brushett, F. R.; Zhang, L.; Wei, X. "Wine-Dark Sea" in an Organic Flow Battery: Storing Negative Charge in 2,1,3-Benzothiadiazole Radicals Leads to Improved Cyclability. ACS Energy Lett. 2017, 2 (5), 1156-1161. https://doi.org/10.1021/acsenergylett.7b00261. 
(10) Vaid, T. P.; Sanford, M. S. An Organic Super-Electron-Donor as a High Energy Density Negative Electrolyte for Nonaqueous Flow Batteries. Chem. Commun. 2019, 55 (74), 11037 11040. https://doi.org/10.1039/C9CC06080D.

(11) Robinson, S. G.; Yan, Y.; Hendriks, K. H.; Sanford, M. S.; Sigman, M. S. Developing a Predictive Solubility Model for Monomeric and Oligomeric Cyclopropenium-Based Flow Battery Catholytes. J. Am. Chem. Soc. 2019, 141 (26), 1017110176. https://doi.org/10.1021/jacs.9b04270.

(12) Zhang, J.; Corman, R. E.; Schuh, J. K.; Ewoldt, R. H.; Shkrob, I. A.; Zhang, L. Solution Properties and Practical Limits of Concentrated Electrolytes for Nonaqueous Redox Flow Batteries. J. Phys. Chem. C 2018, 122 (15), 8159-8172. https://doi.org/10.1021/acs.jpcc.8b02009.

(13) Zeng, Y. K.; Zhao, T. S.; An, L.; Zhou, X. L.; Wei, L. A Comparative Study of All-Vanadium and Iron-Chromium Redox Flow Batteries for Large-Scale Energy Storage. J. Power Sources 2015, 300, 438-443. https://doi.org/10.1016/j.jpowsour.2015.09.100.

(14) Potash, R. A.; McKone, J. R.; Conte, S.; Abruña, H. D. On the Benefits of a Symmetric Redox Flow Battery. J. Electrochem. Soc. 2016, $163 \quad$ (3), A338-A344. https://doi.org/10.1149/2.0971602jes.

(15) Duan, W.; Vemuri, R. S.; Milshtein, J. D.; Laramie, S.; Dmello, R. D.; Huang, J.; Zhang, L.; Hu, D.; Vijayakumar, M.; Wang, W.; Liu, J.; Darling, R. M.; Thompson, L.; Smith, K.; Moore, J. S.; Brushett, F. R.; Wei, X. A Symmetric Organic-Based Nonaqueous Redox Flow Battery and Its State of Charge Diagnostics by FTIR. J. Mater. Chem. A 2016, 4 (15), 5448-5456. https://doi.org/10.1039/C6TA01177B.

(16) Moutet, J.; Veleta, J. M.; Gianetti, T. L. Symmetric, Robust, and High-Voltage Organic Redox Flow Battery Model Based on a Helical Carbenium Ion Electrolyte. ACS Appl. Energy Mater. 2021, 4 (1), 9-14. https://doi.org/10.1021/acsaem.0c02350.

(17) Hendriks, K. H.; Robinson, S. G.; Braten, M. N.; Sevov, C. S.; Helms, B. A.; Sigman, M. S.; Minteer, S. D.; Sanford, M. S. High-Performance Oligomeric Catholytes for Effective Macromolecular Separation in Nonaqueous Redox Flow Batteries. ACS Cent. Sci. 2018, 4 (2), 189-196. https://doi.org/10.1021/acscentsci.7b00544.

(18) Shrestha, A.; Hendriks, K. H.; Sigman, M. S.; Minteer, S. D.; Sanford, M. S. Realization of an Asymmetric Non-Aqueous Redox Flow Battery through Molecular Design to Minimize Active Species Crossover and Decomposition. Chem. Eur. J. 2020, $26 \quad$ (24), 5369-5373. https://doi.org/10.1002/chem.202000749.

(19) Wang, Q.; Zakeeruddin, S. M.; Wang, D.; Exnar, I.; Grätzel, M. Redox Targeting of Insulating Electrode Materials: A New Approach to High-Energy-Density Batteries. Angew. Chem. Int. $E d$. 2006, $45 \quad$ (48), 8197-8200. https://doi.org/10.1002/anie.200602891.

(20) Ye, J.; Xia, L.; Wu, C.; Ding, M.; Jia, C.; Wang, Q. Redox Targeting-Based Flow Batteries. J. Phys. D: Appl. Phys. 2019, 52 (44), 443001. https://doi.org/10.1088/13616463/ab3251.

(21) Huang, Q.; Li, H.; Grätzel, M.; Wang, Q. Reversible Chemical Delithiation/Lithiation of LiFePO4: Towards a Redox Flow Lithium-Ion Battery. Phys. Chem. Chem. Phys. 2013, 15 (6), 1793-1797. https://doi.org/10.1039/C2CP44466F.

(22) Jennings, J. R.; Huang, Q.; Wang, Q. Kinetics of LixFePO4 Lithiation/Delithiation by Ferrocene-Based Redox Mediators:
An Electrochemical Approach. J. Phys. Chem. C 2015, 119 (31), $17522-17528$ https://doi.org/10.1021/acs.jpcc.5b03561

(23) Zanzola, E.; Dennison, C. R.; Battistel, A.; Peljo, P.; Vrubel, H.; Amstutz, V.; Girault, H. H. Redox Solid Energy Boosters for Flow Batteries: Polyaniline as a Case Study. Electrochim. Acta 2017, 235, 664-671. https://doi.org/10.1016/j.electacta.2017.03.084.

(24) Pan, F.; Yang, J.; Huang, Q.; Wang, X.; Huang, H.; Wang, Q. Redox Targeting of Anatase TiO2 for Redox Flow LithiumIon Batteries. Adv. Energy Mater. 2014, 4 (15), 1400567. https://doi.org/10.1002/aenm.201400567.

(25) Yu, J.; Salla, M.; Zhang, H.; Ji, Y.; Zhang, F.; Zhou, M.; Wang, Q. A Robust Anionic Sulfonated Ferrocene Derivative for PH-Neutral Aqueous Flow Battery. Energy Stor. Mater. 2020, 29 ,

216-222. https://doi.org/10.1016/j.ensm.2020.04.020.

(26) Zhu, Y. G.; Du, Y.; Jia, C.; Zhou, M.; Fan, L.; Wang, X.; Wang, Q. Unleashing the Power and Energy of LiFePO4Based Redox Flow Lithium Battery with a Bifunctional Redox Mediator. J. Am. Chem. Soc. 2017, 139 (18), 6286-6289. https://doi.org/10.1021/jacs.7b01146.

(27) Jia, C.; Pan, F.; Zhu, Y. G.; Huang, Q.; Lu, L.; Wang, Q. High-Energy Density Nonaqueous All Redox Flow Lithium Battery Enabled with a Polymeric Membrane. Sci. Adv. 2015, 1 (10), e1500886. https://doi.org/10.1126/sciadv.1500886.

(28) Zhou, M.; Chen, Y.; Salla, M.; Zhang, H.; Wang, X.; Mothe, S. R.; Wang, Q. Single-Molecule Redox-Targeting Reactions for a PH-Neutral Aqueous Organic Redox Flow Battery. Angew. Chem. Int. Ed. 2020, 59 (34), 14286-14291. https://doi.org/10.1002/anie.202004603.

(29) Zhou, M.; Huang, Q.; Pham Truong, T. N.; Ghilane, J.; Zhu, Y. G.; Jia, C.; Yan, R.; Fan, L.; Randriamahazaka, H.; Wang, Q. Nernstian-Potential-Driven Redox-Targeting Reactions of Battery Materials. Chem 2017, 3 (6), 1036-1049. https://doi.org/10.1016/j.chempr.2017.10.003.

(30) Wong, C. M.; Sevov, C. S. All-Organic Storage Solids and Redox Shuttles for Redox-Targeting Flow Batteries. ACS Energy Lett. 2021, 6 (4), 1271-1279. https://doi.org/10.1021/acsenergylett.1c00143.

(31) Vaino, A. R.; Janda, K. D. Solid-Phase Organic Synthesis: A Critical Understanding of the Resin. J. Comb. Chem. 2000, 2 (6), 579-596. https://doi.org/10.1021/cc000046o.

(32) Kowalski, J. A.; Fenton, A. M.; Neyhouse, B. J.; Brushett, F. R. A Method for Evaluating Soluble Redox Couple Stability Using Microelectrode Voltammetry. J. Electrochem. Soc. 2020, 167 (16), 160513. https://doi.org/10.1149/19457111/abb7e9.

(33) The Slower Equilibration Time of the Viologen May Be Due to the Larger Size of the Bn-Bpy-Me2+/+ Cation, Slowing Its Diffusion into and out of the Crosslinked Beads. This Question Is under Further Investigation.

(34) Liang, Z.; Attanayake, N. H.; Greco, K. V.; Neyhouse, B. J.; Barton, J. L.; Kaur, A. P.; Eubanks, W. L.; Brushett, F. R.; Landon, J.; Odom, S. A. Comparison of Separators vs Membranes in Nonaqueous Redox Flow Battery Electrolytes Containing Small Molecule Active Materials. ACS Appl. Energy Mater. 2021, 4 (6), 5443-5451. https://doi.org/10.1021/acsaem.1c00017. 
TOC graphic:

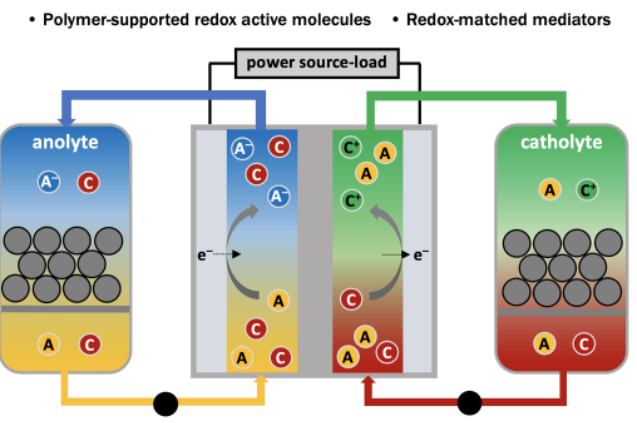

